\title{
Role of complex halides in metal halide lamps
}

\author{
C. HIRAYAMA, C. S. LIU and R. J. ZOLLWEG*
}

\begin{abstract}
Complex vapor compounds of the form $M_{L} n l_{4}$, where $M$ is an alkali metal ion and Ln is a lanthanide or another trivalent ion, play an important role in metal halide arc lamps. such compounds may be the dominant species in the vaporization process and increase the density of desired radiative species in discharge medium. Data are reported from a number of such systems obtained by mass spectroscopic, optical adsorption, vapor transport and lamp characteristic measurements.
\end{abstract}

\section{Introduction}

In recent years there has been an increased emphasis on the development of lamps with higher efficiency and good color rendering index (CRI). This has led to the exploitation of modifications in the high-pressure mercury lamp via the addition of various metal halides ${ }^{1)}$. Some of the metal halides which are found in present commercial lamps are $\mathrm{DyI}_{3}, \mathrm{ScI}_{3}, \mathrm{NaI}, \mathrm{SnI}_{2}$, TII, InI, and LiI. This has resulted in the family of high-intensity discharge (HID) metal halide lamps with good CRI and efficacies as high as 140 lumens/watt (1pw)2), as compared to 50 to $55 \mathrm{lpw}$ with an unsatisfactory bluish color for the pure mercury high-pressure lamp. Not surprisingly, the metal iodides have been most satisfactory as the lamp additives. Three of the more important reasons for this are: (1) the iodides are compatible with silica arc tubes; (2) the iodides are the most compatible of the halides with the tungsten electrodes; and (3) the iodides usually have the highest vapor pressure among compounds of the metals that are suitable as lamp additives. In those HID lamps which contain the covalent iodides, such as indium, thallium, and tin iodides, the quantities of these additives must be limited to control the vapor concentration during lamp operation because of the high vapor pressure of these iodides. However, when the more ionic, less volatile salts are used, such as the alkali and lanthanide iodides, there will nearly always be an excess of the solid or liquid additive. In the latter mixtures, the concentration of the desired radiator in the vapor may be quite low, and any means to increase the vapor pressure tends to improve the lamp efficacy.

In order to effect a significant improvement in the HID lamp, the concentration of the atomic radiator in the electric discharge must be of the

* Westinghouse R \& D Center Pittsburgh, Pennsylvania 15235 order of at least $10^{15}$ atoms $/ \mathrm{cm}^{3}$ at arc temperatures of $4000 \sim 6000 \mathrm{~K}$. Consequently, the vapor pressure of the additive salt in the lamp reservoir, where the temperature is approximately $750^{\circ} \mathrm{C}$, must be at least 0.1 torr. Table 1 shows the temperatures at which the vapor pressure is 0.1 and 1 torr for the lanthanide and scandium iodides, as well as sodium iodide. Those temperatures were calculated from the vapor pressure equations which we obtained for the pure iodides ${ }^{3 \sim 6)}$ 14).

Table 1 Temperatures at which vapor pressures are 1 and $10^{-1}$ torr

\begin{tabular}{l|c|c}
\hline & 1 & $10^{-1}$ \\
\hline $\mathrm{LaI}_{3}$ & 857 & 781 \\
$\mathrm{CeI}_{3}$ & 856 & 777 \\
$\mathrm{PrI}_{3}$ & 838 & 763 \\
$\mathrm{NdI}_{3}$ & 840 & 763 \\
$\mathrm{GdI}_{3}$ & 836 & 764 \\
$\mathrm{TbI}_{3}$ & 841 & 759 \\
$\mathrm{DyI}_{3}$ & 839 & 757 \\
$\mathrm{HoI}_{3}$ & 835 & 762 \\
$\mathrm{ErI}_{3}$ & 824 & 750 \\
$\mathrm{TmI}_{3}$ & 815 & 741 \\
$\mathrm{SmI}_{3}$ & 1091 & 864 \\
$\mathrm{ScI}_{3}$ & 664 & 604 \\
$\mathrm{NaI}$ & 744 & 636 \\
\hline
\end{tabular}

It should be noted that a metal halide lamp usually contains a mixture of iodides, with an alkali iodide, such as NaI, nearly always being added as one of the components. When this mixture becomes molten at the lamp reservoir temperature of approximately $730^{\circ} \mathrm{C}$, the vapor pressure of the components in this mixture will be proportional to their chemical activities, i.e., $P_{i}=a_{i} P_{0 i}$, where $i$ refers to the component, a the activity, and $P_{0}$ is the vapor pressure of the pure component at the reservoir temperature. Because the activity of any component in the molten salt solution is usually less than unity, the vapor pressure of the components are also expected to be lower than the values for the pure 
substance shown in Table 1, in accordance with Raoult's law.

\section{Complex Compounds}

During the course of metal halide lamp development, it had been observed that there was considerable enhancement of the vapor pressure of, for example, $\mathrm{CeI}_{3}$ and $\mathrm{SmI}_{2}$ when these were added together with alkali iodide to the lamp. In the case of $\mathrm{SmI}_{2}$ the enhancement factor was about 103. It became clear during our earlier work that the formation of stable vapor complexes played an important part in the enhanced vapor pressures of lanthanide iodides. Earlier reports in the literature showed the formation of stable complex compounds of some lanthanide chlorides with alkali chlorides.? More recently, it has become more noteworthy that vapor complex compounds play important roles in the chemical equilibria of mixed halide salt systems.9)

Our first direc' evidence for the formation of stable vapor phase complexes between lanthanide iodides and alkali iodides was observed in the mass spectra of vapors of the iodide mixtures.8) 9) Table 2 shows the mass spectra over the equimolar mixtures

Table 2 Mass spectra of vapors over $\mathrm{CsI} \cdot \mathrm{CeI}_{3}$ $1.2 \mathrm{CsI} \cdot \mathrm{CeI}_{3}$, and $\mathrm{CsI} \cdot \mathrm{LaI}_{3}$ measured at $28 \mathrm{eV}$

\begin{tabular}{l|c|c|c}
\hline & $\mathrm{CSI} \cdot \mathrm{CeI}_{3}\left(615^{\circ} \mathrm{C}\right)$ & $1.2 \mathrm{CsI} \cdot \mathrm{CeI}_{3}\left(740^{\circ} \mathrm{C}\right)$ & $\mathrm{CsI} \cdot \mathrm{LaI}_{3}\left(668^{\circ} \mathrm{C}\right)$ \\
\hline $\mathrm{LnI}_{3}{ }^{+}$ & 16 & 12 & 18 \\
$\mathrm{LnI}_{2}{ }^{+}$ & 100 & 100 & 100 \\
$\mathrm{LnI}^{+}$ & 52 & 48 & 65 \\
$\mathrm{Ln}^{+}$ & 88 & 122 & 98 \\
$\mathrm{CsI}^{+}$ & 75 & 74 & 106 \\
$\mathrm{Cs}^{+}$ & 1500 & 1550 & 1410 \\
$\mathrm{CsLnI}_{3}{ }^{+}$ & 9 & 1.5 & 15 \\
$\mathrm{Cs}_{2} I^{+}$ & $<1$ & $\sim 4$ & - \\
\hline
\end{tabular}

$\mathrm{CsI} \cdot \mathrm{CeI}_{3}$ and $\mathrm{CsI} \cdot \mathrm{LaI}_{3}$, and over the mixture 1.2 $\mathrm{CsI} \cdot \mathrm{CeI}_{3}$. We also determined the temperature dependence of the mass spectra and plotted the data as the usual $\log i \mathrm{~T}$ against $1 / \mathrm{T}$, where $\mathrm{i}$ is the ion intensity, $\mathrm{T}$ is the absolute temperature, and $\mathrm{i} \mathrm{T}$ is proportional to the partial pressure of the particular ion. The plotted data showed parallel temperature dependence for all of the ions, except $\mathrm{Cs}_{2} \mathrm{I}^{+}$. This latter ion, which originates from $\mathrm{Cs}_{2} \mathrm{I}_{2}$, was either below the detection limit or its intensity was too low to allow a good measure of its relative intensity. The $\mathrm{CsLnI}_{3}{ }^{+}$ion in the mass spectra originates from the $\mathrm{CsLnI}_{4}(\mathrm{~g})$ complex compound when its species is ionized by electron impact. The parallel temperature dependence of the ion relative intensities suggests that these ions originate from the same parent compond. Also, the absence, or very low partial pressure, of the cesium iodide dimer shows that the complex compound dominates the vapor phase. If there is significant vaporization of cesium iodide, its vaporization equilibrium would dictate a significant concentration of the dimer, $\left.\mathrm{Cs}_{2} \mathrm{I}_{2}{ }^{8}\right)$ The complex compound is the domi- nant species in the vapor, but as the $\mathrm{CsI} / \mathrm{CeI}_{3}$ ratio becomes greater than unity in the condensed phase, free CsI vaporization begins to contribute, and the $\mathrm{Cs}_{2} \mathrm{I}_{2}(\mathrm{~g})$ concentration will increase, as shown for the $1.2 \mathrm{CsI} \cdot \mathrm{CeI}_{3}$ mixtures. On comparing our observations of the iodide mass spectra with that of $\mathrm{CsCl} \cdot \mathrm{NdCl}_{3}$, as reported by Gavryuchenkov and Novikov ${ }^{10}$, it is clear that the lanthanide iodides have a greater tendency to form vapor complexes than do the chlorides. The latter system showed significant contribution of cesium chloride vaporization.

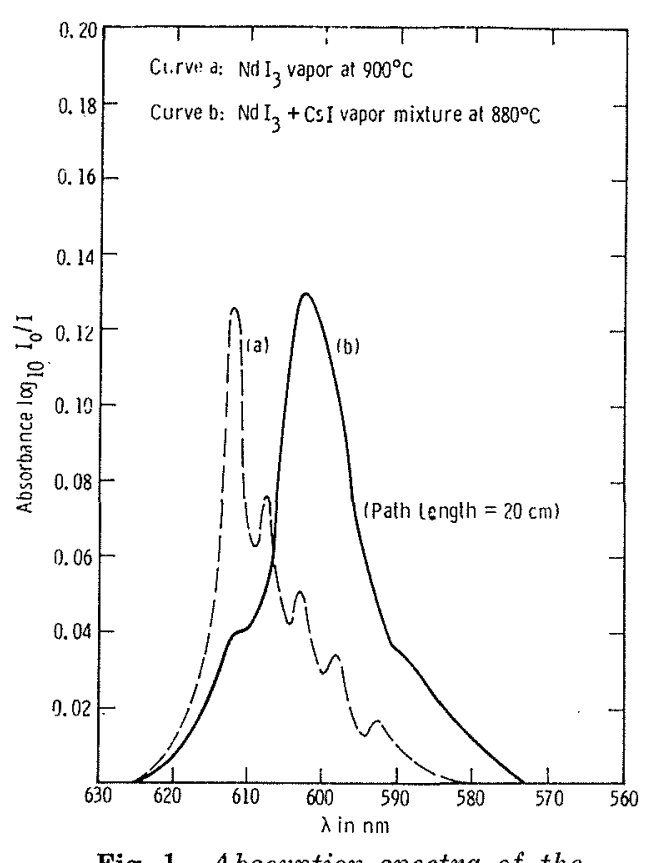

Fig. 1 Absorption spectra of the $N d^{3+}{ }^{4} I_{9 / 2}-{ }^{4} G_{5 / 2}$ transition

Further evidence for the formation of $\mathrm{CsCeI}_{4}(\mathrm{~g})$ and $\mathrm{CsNdI}_{4}(\mathrm{~g})$ complexes was observed in the optical absorption spectra of the vapors over the iodide mixtures. ${ }^{11)}$ In an optical cell containing equimolar quantities of solid $\mathrm{NdI}_{3}$ and CsI heated to $900^{\circ} \mathrm{C}$, the absorption spectrum of this vapor mixture was completely different from that of either CSI vapor or $\mathrm{NdI}_{3}$ vapor alone and is illustrated in Fig. 1. The strongest maximum occurred at $\sim 602 \mathrm{~nm}$, while the strongest one for pure $\mathrm{NdI}_{3}$ vapor was located at $\sim 612 \mathrm{~nm}$. This new absorption band originated from the $\mathrm{Nd}^{3+4} \mathrm{I}_{9 / 12} \rightarrow{ }^{4} \mathrm{G}_{5 / 12}$ transition. In this combined absorption spectrum one observed very little pure $\mathrm{NdI}_{3}$ vapor absorption $(<5 \%)$ thus showing that the vapor phase of the comple mixture consisted predominantly of the complex molecules. The neodymium species vaporization enhancement due to the formation of complex molecules in the $\mathrm{NdI}_{3}+\mathrm{CsI}$ system was calculated to be a factor 3 at $\sim 900^{\circ} \mathrm{C}$ and 6 at $\sim 800^{\circ} \mathrm{C}$.

During the mass spectrometric and vaporization studies, we observed that the lanthanide iodides formed vapor complexes more readily with CsI than with NaI. For example, the mass spectrum of the vapors over the $\mathrm{NaI} \cdot \mathrm{CeI}_{3}$ mixture shows a signifi- 
cant contribution from the vaporization of sodium iodide, as evidenced by the significant partial pressure of $\mathrm{Na}_{2} \mathrm{I}_{2}(\mathrm{~g})$. Also, there was a preferential vaporization of $\mathrm{NaI}$ from this mixture when it was heated in the Knudsen cell.

The mass spectra over the ScI $_{3}$-alkali iodide systems also were investigated.12) In this system it appeared that the $\mathrm{NaI}_{-} \mathrm{ScI}_{3}$ combination has the strongest tendency to form the vapor complex. It was found that the complex, $\mathrm{Na}_{2} \mathrm{ScI}_{5}(\mathrm{~g})$, may make a significant contribution to the vapor phase composition over this binary iodide mixture. However, the $\mathrm{NaScI}_{4}(\mathrm{~g})$ is the dominant species over this mixture.

As shown above, $\mathrm{ScI}_{3}$ and the lanthanide triiodides readily formed the stable vapor complexes with alkali iodides in the temperature range of interest to HID lamps. On the other hand, our mass spectrometric and vapor pressure studies of the CsI-SmI $I_{2}$ and $\mathrm{NaI}-\mathrm{SmI}_{2}$ systems in this temperature range showed only a weak tendency for the formation of $\mathrm{CsSmI}_{3}(\mathrm{~g})$; the $\mathrm{NaSmI}_{3}(\mathrm{~g})$ was not detected. ${ }^{9)}$ Nevertheless, spectroscopic measurements of lamps which contained $\mathrm{SmI}_{2}, \mathrm{CeI}_{3}, \mathrm{CsI}$, and $\mathrm{NaI}$ had shown that there was approximately a 103 enhancement of the $\mathrm{SmI}_{2}$ vaporization with this combination in the HID lamp. ${ }^{13}$ ) This latter enhancement is attributed to the effect of high mercury pressure (see below).

\section{Vapor Pressure Enhance- ment}

It is of interest to determine the magnitude of vapor pressure enhancement and also to consider the thermodynamics of the halide mixture system.

The mass spectrometric ${ }^{8) 9}$ and optical absorption $^{11}$ measurements of most of these iodide systems showed the predominance of the $\operatorname{MLnI}_{4}(\mathrm{~g})$ in the vapor, where $\mathrm{M}$ is the alkali metal and $\mathrm{Ln}$ is the lanthanide or scandium ion. Vapor pressure measurements were made on these systems by optical absorption, boiling point, and vapor transpiration techniques in the higher pressure region; the Knudsen cell technique was used in the low pressure region. In calculating the vapor pressure from the Knudsen cell and transpiration measurements, it was assumed that the $\mathrm{MLnI}_{4}(\mathrm{~g})$ was the dominant species. The agreement between optical absorption, boiling point, and Knudsen cell measurements for $\mathrm{CsI} \cdot \mathrm{CeI}_{3}$ was satisfactory. Fig. 2 shows the vapor pressures over $\mathrm{NaI} \cdot \mathrm{ScI}_{3}, \mathrm{CsI} \cdot \mathrm{LaI}_{3}$, and $\mathrm{CsI} \cdot \mathrm{CeI}_{3}$ as compared to the vapor pressures of $\mathrm{ScI}_{3}$, $\mathrm{LaI}_{3}, \mathrm{CeI}_{3}, \mathrm{CsI}$, and $\mathrm{NaI}$. The vapor pressure data for the alkali iodide are those of Topor. ${ }^{14)}$ As it is seen, there is significant enhancement of the vapor pressures of the $\mathrm{LnI}_{3}$ via vapor complex formation. In the case of the lanthanides the vapor pressure of the complex is at least 0.1 torr at lamp operating temperatures of $\sim 1000 \mathrm{~K}$, an enhancement of approximately fourfold for the lanthanide.

We have observed in the CsI-lanthanide trriodide systems that the vapor pressure of the complex is

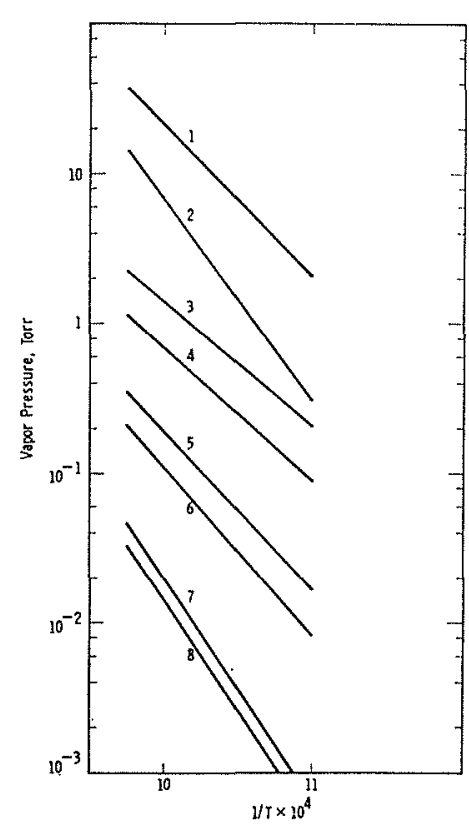

Fig. 2 Vapor pressures over: 1: $\mathrm{NaI} \cdot \mathrm{ScI}_{3}, \quad 2: \mathrm{ScI}_{3}, \quad 3$ $\mathrm{CsI}, 4: \mathrm{NaI}, 5: \mathrm{CsI} \cdot \mathrm{LaI}_{3}$ 6: $\mathrm{CsI} \cdot \mathrm{CeI}_{3}, \quad 7: \mathrm{CeI}_{3}, \quad 8$ : $\mathrm{LaI}_{3}$

intermediate between those of the $\mathrm{CsI}$ and $\mathrm{LnI}_{3}$, as shown in Fig. 2 for $\mathrm{CsCeI}_{4}$ and $\mathrm{CsLaI}_{4}$. However, in the alkali iodide-ScI 3 systems, the vapor pressure of the complex is appreciably higher than that of both the $\mathrm{ScI}_{3}$ and the alkali iodide. ${ }^{15}$ ) In these systems there is enhancement of both the $\mathrm{ScI}_{3}$ and the alkali iodides.

The mass spectrometric and vaporization studies of the $\mathrm{SmI}_{2}-\mathrm{MI}$ systems showed that there was no vapor pressure enhancement of the $\mathrm{SmI}_{2}$ via complex formation. However, the arc measurements on experimental lamps which contained $\mathrm{SmI}_{2}$ and alkali iodides showed that the samarium atom density was of the order of $10^{15}$ atoms $/ \mathrm{cm}^{3}{ }^{13)}$. This showed $\sim 10^{3}$ enhancement of the $\mathrm{SmI}_{2}$ vapor pressure. It was observed in the optical absorption measurements of $\mathrm{CsI} \cdot \mathrm{NdI}_{3}$ in a high-pressure mercury vapor atmosphere that there was an interaction between the complex and mercury, as shown by changes in the absorption spectra.11)

It is of interest here to consider the reason for the predominance of the vapor complex over the mixed iodide system. For the system,

$$
\operatorname{LnI}_{3}(\mathrm{~g})+\mathrm{MI}(\mathrm{g}) \rightarrow \operatorname{MLnI}_{4}(\mathrm{~g})
$$

the enthalpy of formation of the $\mathrm{MLnI}_{4}(\mathrm{~g})$ from the respective iodides is $\sim-85 \mathrm{kcal} / \mathrm{mole},-57$ $\mathrm{kcal} / \mathrm{mole}$, and $-67 \mathrm{kcal} / \mathrm{mole}$, respectively for $\mathrm{NaScI}_{4}(\mathrm{~g}), \mathrm{CsNdI}_{4}(\mathrm{~g})$ and $\mathrm{CsCeI}_{4}(\mathrm{~g})$.

For other $\operatorname{MLnX}_{4}(\mathrm{~g})$ systems the enthalpy of formation is $\sim-60 \mathrm{kcal} / \mathrm{mole}$. In contrast, the dimerization energies for the $\mathrm{MI}$ and $\mathrm{LnI}_{3}$ are $\sim-50 \mathrm{kcal} / \mathrm{mole}$. The formation of the $\mathrm{MLnI}_{4}(\mathrm{~g})$ complex, therefore, results in a stabilization energy of at least $10 \mathrm{kcal} / \mathrm{mole}$ for the mixed iodide system. 
It is important to consider another aspect of the stabilization of $\mathrm{LnI}_{3}$ in mixed iodide systems. To date, all practical metal halide lamps use fused silica envelopes. It is well established that the $\mathrm{LnI}_{3}$ react with silica at the temperatures of metal halide lamp operation, and that a silicate is formed as a reaction product on the arc tube wall. In the case of $\mathrm{ScI}_{3}$, this reaction may be represented by

$$
2 \mathrm{ScI}_{3}+3.5 \mathrm{SiO}_{2} \rightarrow \mathrm{Sc}_{2} \mathrm{Si}_{2} 0_{7}+1.5 \mathrm{SiI}_{4}(\mathrm{~g})
$$

The free energy change for reaction (2) at $1000 \mathrm{~K}$ is approximately $10 \mathrm{kcal}$, so that the equilibrium constant is $\mathrm{K} \approx-148$. This constant is a relatively small negative value, and should the $\mathrm{SiI}_{4}(\mathrm{~g})$ be removed from the system by dissociation at the hot electrode the reaction will tend to proceed to the right. However, a large part of the $\mathrm{ScI}_{3}$, as well as any other $\operatorname{LnI}_{3}$, in a lamp is present in the molten phase as the complex salt in solution with the alkali iodide, so that the chemical activity of the $\mathrm{ScI}_{3}$ is much reduced. As a matter of fact, the formation of the complex $\mathrm{NaScI}_{4}$ in the condensed phase also results in a stabilization energy of at least $10 \mathrm{kcal} /$ mole over that of $\mathrm{ScI}_{3}$. Therefore, the reaction

$$
\begin{gathered}
2 \mathrm{NaScI}_{4}(l)+3.5 \mathrm{Si}_{2}(\mathrm{c}) \rightarrow \\
\mathrm{Sc}_{2} \mathrm{Si}_{2} 0_{7}(\mathrm{c})+1.5 \mathrm{SiI}_{4}(\mathrm{~g})+2 \mathrm{NaI} \text { (in solution) }
\end{gathered}
$$

is significantly less favorable than reaction (2). This is the reason for the improved compatibility of the $\mathrm{LnI}_{3}$ with the silica envelope in metal halide lamps.

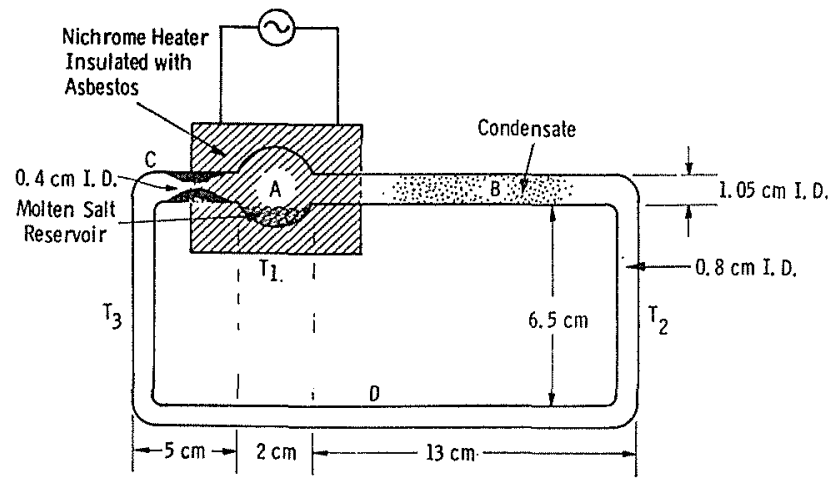

Fig. 3 High pressure vapor transport tube

We further investigated the effect of high-pressure mercury vapor on the vaporization, especially of $\mathrm{SmI}_{2}$, by utilizing a silica, high-pressure vapor transpiration apparatus, as shown in Fig. 3. Details of this experiment have been described.9) The fused salt temperature $\mathrm{T}_{1}$, was at $650^{\circ} \mathrm{C}, \mathrm{T}_{2}$ was $485^{\circ}$, and $\mathrm{T}_{3}-\mathrm{T}_{2} \approx 5^{\circ}$. The tube contained saturated mercury vapor or xenon, and the pressure in the closed tube was $\sim 8$ atmospheres. The transported material was always collected in zone $B$ and subsequently analyzed for alkali and lanthanide. The data in Table 3 show two significant aspects. The first is the enhancement of the vaporization of the samarium when it is present as a molten salt mixture with $\mathrm{CsI}$ and $\mathrm{NaI}$. The second is the enhancement of the vaporization in high-pressure mercury, as com-
Table 3 Vapor transport of iodides in 8 atm of $\mathrm{Hg}$ and $\mathrm{Xe}$ in 240 hours. Molten salt temperature $=650^{\circ} \mathrm{C}$

\begin{tabular}{l|c|c|c|c|c|c}
\hline \multirow{2}{*}{$\begin{array}{l}\text { Molten Salt } \\
\text { Composition }\end{array}$} & $\begin{array}{c}\text { High } \\
\text { Pressure } \\
\text { Gas }\end{array}$ & \multicolumn{3}{|c|}{$\begin{array}{c}\text { Millimoles } \times 10^{3} \\
\text { Vaporized }\end{array}$} & Alkali/Ln \\
\cline { 3 - 6 } & $\mathrm{Ng}$ & $\mathrm{Cs}$ & $\mathrm{Sm}$ & $\mathrm{Ce}$ & \\
\hline $\mathrm{SmI}_{2}$ & $\mathrm{Hg}$ & & & 0.014 & & \\
$2 \mathrm{SmI}_{2} \cdot \mathrm{CeI}$ & $\mathrm{Hg}$ & & 0.0016 & & \\
$\mathrm{SmI}_{2} \cdot 2 \mathrm{NaI}$ & $\mathrm{Hg}$ & & & 0.075 & 0.0029 & 19 \\
$\mathrm{SmI}_{2} \cdot 2 \mathrm{CsI}$ & $\mathrm{Hg}$ & & 1.98 & 0.083 & & 24 \\
$\mathrm{SmI}_{2} \cdot 2 \mathrm{CsI}$ & $\mathrm{Xe}$ & & 1.0 & 0.005 & & 200 \\
$\mathrm{SmI}_{2} \cdot \mathrm{NaI} \cdot \mathrm{CsI}$ & $\mathrm{Hg}$ & 0.84 & 0.65 & 0.065 & & 23 \\
$\mathrm{CsI}_{\mathrm{CeI}}$ & $\mathrm{Hg}$ & & 0.13 & 0.076 & & 1.7 \\
$\mathrm{CsI}_{3} \cdot \mathrm{CeI}_{3}$ & $\mathrm{Xe}$ & & 0.25 & 0.056 & & 4.5 \\
\hline
\end{tabular}

pared to that in high-pressure xenon. In this latter aspect, the effect of the mercury on the CsI. SmI vaporization is appreciably greater than that on the CsI. $\mathrm{CeI}_{3}$. The greater enhancement of samarium vaporization is consistent with the observations in lamps which contain these iodides. The exact mechanism for the enhanced vaporization by highpressure $\mathrm{Hg}$ is not known, but one might speculate that the mercury forms short lived complex species with the MI. SmI in the vapor, or that the highpressure $\mathrm{Hg}$ may form clusters with the iodides.

\section{Enhanced vaporization and lamp performance}

The effect of enhanced vaporization by formation of a volatile complex is clearly shown by the lamp spectra in Fig. 4. The spectra of these two lamps were taken at identical lamp power and detector gain. The spectrum of lamp $\mathrm{A}$, with a $\mathrm{NaI} / \mathrm{ScI}_{3}$ ratio of 2, shows significantly larger amounts of radiation from both $\mathrm{Na}$ and $\mathrm{Sc}$, as compared to lamp B with $\mathrm{NaI} / \mathrm{ScI}_{3}$ ratio of 30 . We have observed similar effects in experimental lamps filled with $\mathrm{LiI}_{-\mathrm{ScI}}$ mixtures, ${ }^{16)}$ where the $\mathrm{ScI}_{3}$ vapor pressure enhancement is greater than in the $\mathrm{NaI}-\mathrm{ScI}_{3} \mathrm{mix}$ ture. ${ }^{15)}$ It may be noted here that lamp arc measurements and calculations ${ }^{17}$ are consistent with the enhanced vaporization by complex formation.

Fig. 5 shows the spectra of lamps filled with $\mathrm{SmI}_{2}, \mathrm{CsI}$, and $\mathrm{NaI}$, in addition to $\mathrm{Hg}$ and $\mathrm{Ar}$. The latter is used as the starting gas. The lamp with only $\mathrm{SmI}_{2}$ contained $150 \mathrm{mg} \mathrm{Hg}(\sim 9$ atm at the lamp temperature of $\sim 5000 \mathrm{~K}$ ), whereas the other two lamps contained $40 \mathrm{mg} \mathrm{Hg}(\sim 3 \mathrm{~atm})$. Note that the spectra for the lamp with $\mathrm{SmI}_{2}$, Fig. 5c, was recorded at a gain factor ten times greater than those in Figs. 5a and 5b. Aside from the mercury lines, the spectra are dominated by the samarium atomic radiation which is almost continuous. The cesium radiation is in the infrared, while Fig. $5 \mathrm{~B}$ also shows the strong sodium radiation. Fig. 5 shows that the samadium radiation from the lamp with $\mathrm{NaI} \cdot \mathrm{SmI}_{\mathbf{2}}$ is approximately tenfold greater than that from the lamp with $\mathrm{SmI}_{2}$. The samarium radiation from the lamp with $\mathrm{CsI} \cdot \mathrm{SmI}$ is increased by at least twofold over that of the $\mathrm{NaI} \cdot \mathrm{SmI}_{2}$ lamp. The lamp spectra therefore show that the apparent 

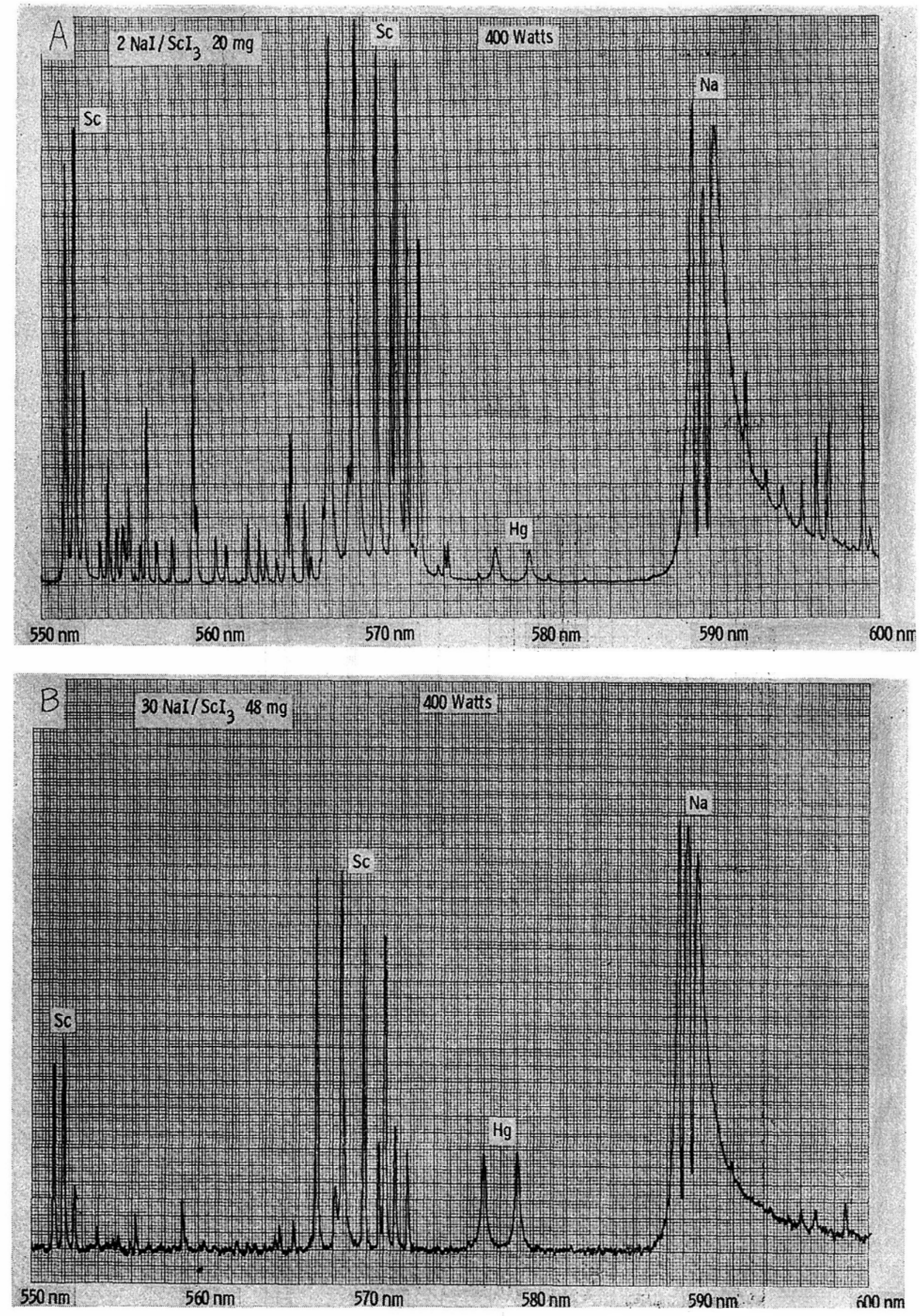

Fig. 4 Spectra of $\mathrm{NaI}-\mathrm{ScI}_{3}$ lamps. A:2NaI $\cdot \mathrm{ScI}_{3} ; \mathrm{B}: 30 \mathrm{NaI} \cdot \mathrm{ScI}_{3}$ 


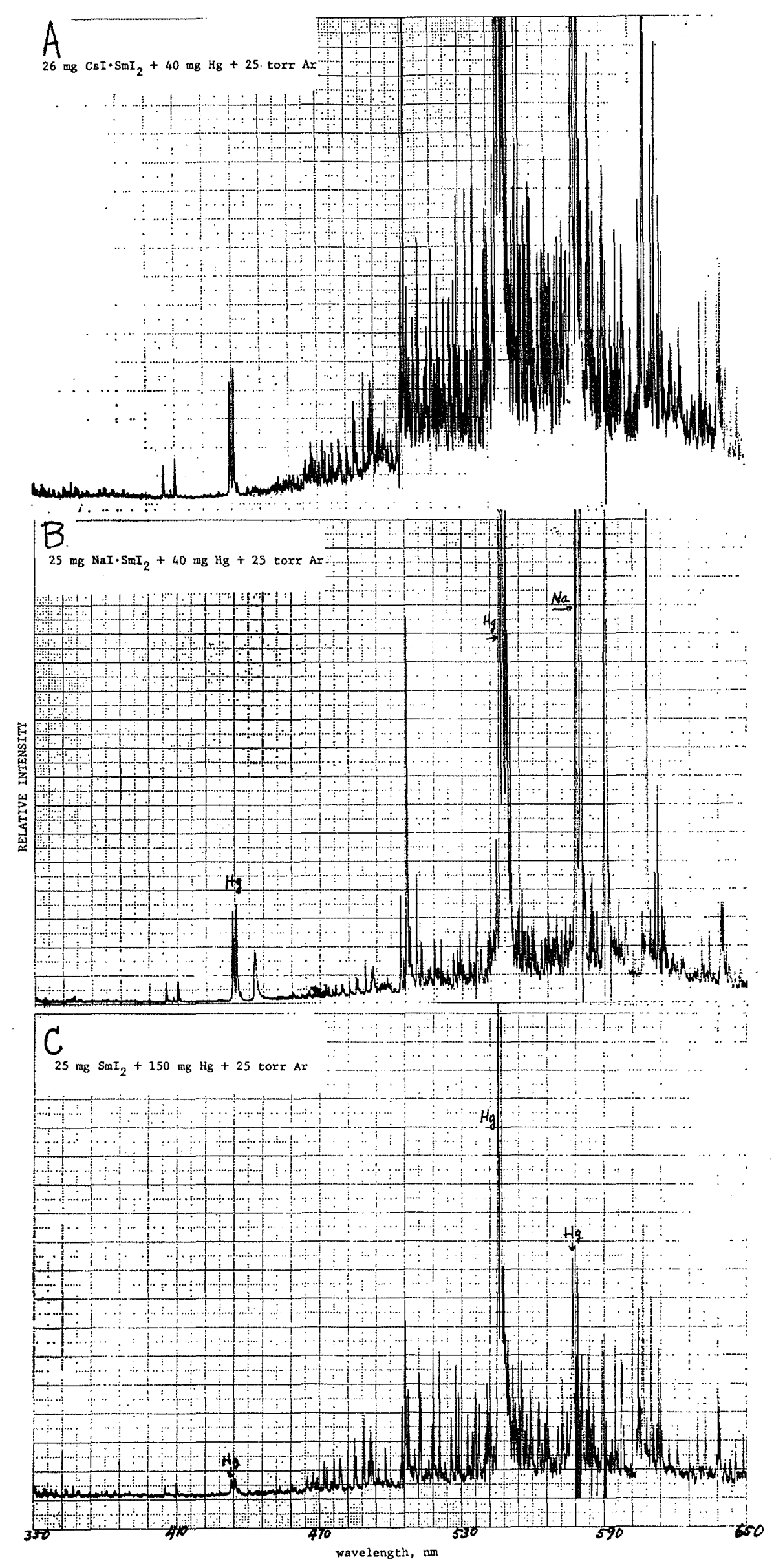

Fig. 5 Lamp spectra. Gain factor of $C$ is $10 \mathrm{X}$ those of $A$ and $B$ 
samarium concentration is in the ratio of $\sim 20: 10: 1$ in the lamps with $\mathrm{CsI} \cdot \mathrm{SmI}_{2}, \mathrm{NaI} \cdot \mathrm{SmI}_{2}$, and $\mathrm{SmI}_{2}$, respectively. More detailed measurements taking into account the temperature profile and possible segregation would be necessary to determine the true samarium concentration.

In summary, it has been shown that the formation of vapor complex compounds plays an important role in the operation of metal-halide HID lamps. The vapor pressure enhancement which results from complex formation can result in higher lamp efficiency and better CRI. The vapor pressure enhancement factors can vary over a wide range, depending on the halide. The effect of the high mercury pressure also must be considered, as demonstrated in the case of $\mathrm{SmI}_{2}$.

\section{References}

(1) R. Lorenz : Lighting Design and Technol. 8 (1976) 136.

(2) M. Saito, M. Tsuchihashi, K. Watanabe and $K$. Baba: Paper presented at Illum. Engng. Soc., Nat. Tech. Conf., Atlantic City, NJ, USA, Sept. 16-20 (1979).

(3) C. Hirayama, J. F. Rome, F. E. Camp : J. Chem. Eng. Data, 20 (1975) 1.

(4) C. Hirayama, P. M. Castle, R. W. Liebermann, R. J. Zollweg, F. E. Camp : Inorg. Chem. 13 (1974) 2804.
(5) C. Hirayama, G. L. Carlson, P. M. Castle, J. F. Rome, W. E. Snider: J. Less-Comm. Metals 45 (1976) 301.

(6) C. Hirayama, P. M. Castle, R. L. Kleinosky, W. E. Snider: Vapor Pressure of $\mathrm{ScI}_{3}, \mathrm{~J}$. Less-Comm. Metals 57 (1978) 69.

(7) G. I. Novikov and F. G. Gavryuchenkov : Russian Chem. Rev. 36(1967) 156 (Engl. transl.).

(8) C. Hirayama and P. M. Castle: Proc. 11th Rare Earth Res. Conf. 1974, Vol. II, p. 1048.

(9) C. Hirayama, C. S. Liu, R. J. Zollweg, P. M. Castle : Proc. 12th Rare Earth Res. Conf., 1976 , Vol. II, 1044.

(10) F. G. Gavryuchenkov and G. I. Novikov: Vestnik Lenningrad Univ. 21 (1966) 108.

(11) C. S. Liu and R. J. Zollweg: J. Chem. Phys. 60 (1974) 2384.

(12) P. M. Castle and C. Hirayama : unpublished work.

(13) R. J. Zollweg: J. Illum. Engng. Soc. 5 (No. 1), (1975) 12.

(14) L. Topor : J. Chem. Thermodyn. 4 (1972) 739.

(15) C. Hirayama, C.S. Liu, R. J. Zollweg, P. M. Castle: J. Illum. Engng. Soc. 6 (No. 4), (1977) 209

(16) C. S. Liu, C. Hirayama, R. J. Zollweg, R. A. Madia : U.S. Patent 3,979,624 (1976).

(17) R. J. Zollweg and R. W. Liebermann : Proc. Symp. on High Temperature Metal Halide Chemistry, Proceedings Vol. 78-1, The Electrochemical Society, Inc. (1978).

Received 12 Dec. 1980 